\title{
Awareness, knowledge and attitudes of Guyanese undergraduate students towards the human papillomavirus (HPV) and its vaccine
}

\author{
Audrey Thomas ${ }^{1}$, Phillip N.B. Da Silva ${ }^{1,{ }^{*}}$ and Dharamdeo Singh ${ }^{2}$ \\ ${ }^{1}$ Faculty of Natural Sciences, University of Guyana Berbice Campus, Tain, Guyana. \\ ${ }^{2}$ Faculty of Agriculture Science, University of Guyana Turkeyen Campus, Guyana.
}

GSC Biological and Pharmaceutical Sciences, 2021, 14(02), 115-125

Publication history: Received on 15 January 2021; revised on 08 February 2021; accepted on 13 February 2021

Article DOI: https://doi.org/10.30574/gscbps.2021.14.2.0046

\begin{abstract}
Although cervical cancer is a leading cause of death among Guyanese women, there still appears to be a low uptake rate for the HPV vaccine. The objective of this study was to conduct a preliminary investigation of the knowledge, awareness and attitudes of undergraduate students towards HPV and the HPV vaccine. A cross sectional study was conducted, using a stratified random sampling procedure with a 25\% (164 respondents) sample at a tertiary institution in Guyana. A 40-item questionnaire was used in this study. Cronbach's alpha for reliability of the research instrument was 0.81 . The research instrument addressed questions on demographic characteristics of respondents, awareness, knowledge and attitudes and source of information about HPV and the HPV vaccine. The majority of respondents were females. Although 83.5\% of respondents had a prior awareness of either HPV or the HPV vaccine, none of the respondents had ever received the HPV vaccine. Respondents had a somewhat fair level of knowledge about HPV and the HPV vaccine. There was a statistically significant difference between male and female students in the mean HPV knowledge, attitudes and willingness to accept the HPV vaccine. Only $40.9 \%$ of respondents were willing to take the HPV vaccine. The decision to not want to take the HPV vaccine was influenced by several factors. The observed differences and gender influences can have implications for local HPV education and awareness programmes and strategies.
\end{abstract}

Keywords: Human papillomavirus; Knowledge; Awareness; Attitudes; Guyana

\section{Introduction}

Human papillomavirus (HPV) infection is sexually transmitted and has the potential, to cause genital warts and cervical cancer [1] [2]. Globally, cervical cancer is among the most commonly diagnosed forms of cancer in females [3] and has been identified as a prevalent type of cancer in developing countries [4]. Contracting HPV is often considered a risk factor for developing cervical cancer which has been linked to substantial mortality worldwide, with cancer of the uterine cervix named the second most common cancer in women [5] [6].

While cervical cancer has been identified as a very common form of cancer in females globally, statistics for Guyana has shown that approximately 160 women are diagnosed with cervical cancer and there are about 75 deaths annually [7] [8]. However, although reportedly one of the leading causes of death among women in Guyana, not many persons appear to appreciate the necessity and urgency to ensure that young females are vaccinated in an effort to either prevent or reduce HPV infection.

While there are known advantages of being vaccinated for HPV, it is likely that acceptance of the HPV vaccine may be dependent on a good knowledge about HPV and its link to cervical cancer. Also, what is important to note is that

\footnotetext{
${ }^{*}$ Corresponding author: Phillip N.B. Da Silva

Faculty of Natural Sciences, University of Guyana Berbice Campus, Tain, Guyana.

Email address: phillip.dasilva@uog.edu.gy

Copyright (C) 2021 Author(s) retain the copyright of this article. This article is published under the terms of the Creative Commons Attribution Liscense 4.0.
} 
although vaccination programmes appear to target young girls, the vaccine can also be given to young males and it has proven to be effective [9].

Previous studies have reported on knowledge of HPV and HPV vaccines and the results of these studies have indicated somewhat low levels of knowledge. These results may be interpreted as respondents having a lack of or a low-level knowledge and awareness about the issues surrounding HPV and HPV infections such as the cause, transmission, prevention of HPV and cervical cancer [10] [[8] [11] [4]. [12] investigated the factors that influenced the willingness to accept the HPV vaccine and reported that attitudes and beliefs were greater influences on willingness to accept the HPV vaccine than was knowledge about the HPV vaccine.

Despite the abundance of literature on HPV vaccination, few studies exploring changing perceptions of stakeholders following the introduction of HPV vaccination appear to have been conducted in developing countries amid concerns about quality of delivery; safety, adverse effects and the effects of the vaccination on girls' fertility [13]. Though adolescents are the prime candidates for prophylactic HPV vaccination, several studies have shown that adolescents had very little knowledge about HPV vaccines. This lack of knowledge might adversely affect the acceptance of the HPV vaccine [13] [14].

With cervical cancer recognized as a leading common type of cancer affecting Guyanese women, local data shows an average annual incidence rate of 46.9 out of every 100,000 persons in the population. Sixty-six percent (66\%) or two out of every three Guyanese women with cervical cancer are below the age of 60 and females between the ages of 1544 years are in the group with the highest risk of developing cervical cancer. Further, according to estimates for 2018, annually, approximately one hundred and twenty-four new cases of cervical cancer are diagnosed in Guyana [15].

In 2015, the Ministry of Health in Guyana initiated a HPV vaccination programme that targeted 11-year old school aged girls [8]. [8] reported on a study which sought to examine the knowledge and awareness of HPV and its vaccine and concluded that there was a need for educational programmes and activities to ensure a greater level of acceptance and meaningful participation of stakeholders in the programme. In 2017, the HPV vaccination programme was relaunched by the Ministry of Public Health (MOPH) in collaboration with the Pan American Health Organization/ World Health Organization (PAHO/WHO) and the United Nations Children's Fund (UNICEF) to help address the rising number of cervical cancer cases.

At this time, still the number of cases of cervical cancer in Guyana is increasing and so it may be assumed that there is still a need to address the issue of awareness, knowledge and attitudes of persons, if the Ministry of Public Health is to develop effective strategic measures for implementing and sustaining any HPV vaccination programme.

This study was conducted to assess the knowledge, awareness and attitudes of undergraduate students at a Guyanese tertiary institution about HPV and the HPV vaccine. The results from this study may provide useful information for improving the HPV vaccination programme in Guyana.

\section{Material and methods}

\subsection{Study location}

This study was carried out at the Johns' Science Centre and Tain Campus of the University of Guyana Berbice Campus (UGBC).

\subsection{Methods}

\subsubsection{Ethical Consideration}

Student participation was voluntary. The importance and purpose of this research were explained and all information obtained from the participants was kept confidential.

\subsubsection{Data Collection}

A cross sectional study was done using a stratified random sampling procedure. The 40 -item questionnaire used in this study was pilot tested at the Turkeyen Campus of the University of Guyana. Cronbach's alpha for the reliability of the research instrument was 0.81 . All necessary changes were made to the questionnaire after the pilot test was completed and the amended questionnaire was then distributed to consenting respondents at the Tain campus and John's Science Centre of the UGBC. 
A $25 \%$ sample size of the total student population at UGBC was used in this study. Permission was sought and obtained from the administrators of the UGBC. The rights of respondents for anonymity and confidentiality were ensured and respected and their informed consent was obtained before the questionnaire was administered.

Respondents were asked to complete a self-administered questionnaire which had four (4) sections, with each section focusing on a different aspect.

- $\quad$ Section A - Demographic characteristics of respondents

- $\quad$ Section B - Awareness and knowledge of Human papillomavirus and its infections

- $\quad$ Section C- Awareness, knowledge and attitude towards the HPV vaccine

- $\quad$ Section D- Source of information about the HPV vaccine

\subsubsection{Statistical analysis}

All statistical analyses were conducted using the Statistical Package for Social Sciences Version 23 (SPSS v23). The data were entered in SPSS v23 and analyzed using descriptive and inferential statistics. A measure of significance, using ANOVA and student t-test at the $5 \%$ level was conducted.

\section{Results and discussion}

\subsection{General demographic characteristics of respondents}

In this study, 164 respondents completed the self-administered study questionnaire. The general biodata profile of respondents (Table 1) shows that the majority of respondents (35\%) was in the 16 - 20 years age group and the least $(8 \%)$ was in the above 32 years age group. Noteworthy is the observation that $68.3 \%$ of respondents were females, since most of the males who were approached to complete the questionnaire were reluctant to do so. $78.9 \%$ of all respondents were single or not married. In terms of sexual activity, 43 (26.2\%) of all respondents reported that they were sexually active and 3 (1.8\%) reported ever having a sexually transmitted infection. Although $85.5 \%$ of the respondents surveyed had previously either heard about HPV or the HPV vaccine, the results revealed that none of the respondents had ever received the HPV vaccine.

In terms of the distribution of respondents based on Faculty, 31.2\% were from the Division of Social Sciences, $29.9 \%$ were from the Division of Education and 18.2\% were from the Division of Natural Sciences. This is in keeping with the student population size of the respective academic Divisions, where the largest student population is from the Division of Social sciences, followed by the Division of Education and then the Division of Natural sciences. The School of Entrepreneurship and Business Innovation and the Division of Agriculture have the smallest student populations on the campus and respondents in this survey made up $14.6 \%$ and $6.1 \%$ respectively.

Table 1 General biodata profile of study sample

\begin{tabular}{|l|l|l|}
\hline Variable & Frequency & Percentage \\
\hline GENDER & & \\
\hline Male & 52 & 31.7 \\
\hline Female & 112 & 68.3 \\
\hline AGE GROUP (years) & & \\
\hline $16-20$ & 58 & 35 \\
\hline $21-24$ & 44 & 27 \\
\hline $25-28$ & 28 & 17 \\
\hline $29-32$ & 21 & 13 \\
\hline Above 32 & 13 & 8 \\
\hline ETHNIC GROUP & & \\
\hline Afro Guyanese & 71 & 43.3 \\
\hline
\end{tabular}




\begin{tabular}{|l|l|l|}
\hline Variable & Frequency & Percentage \\
\hline Indo Guyanese & 62 & 37.8 \\
\hline Other & 31 & 18.9 \\
\hline MARITAL STATUS & & \\
\hline Single & 131 & 78.9 \\
\hline Married & 33 & 20.1 \\
\hline RELIGION & & \\
\hline Hindu & 39 & 23.8 \\
\hline Muslin & 49 & 29.9 \\
\hline Christian & 61 & 37.2 \\
\hline Other & 15 & 9.1 \\
\hline FACULTY & & \\
\hline School of Entrepreneurship and Business Innovation & 24 & 14.6 \\
\hline School of Education \& Humanities & 49 & 29.9 \\
\hline Division of Agriculture & 10 & 6.1 \\
\hline Division of Natural Science & 30 & 18.2 \\
\hline Division of Social Science & 51 & 31.2 \\
\hline SEXUALLY ACTIVE & & \\
\hline Yes & 164 & 100 \\
\hline No & 161 & 93.2 \\
\hline EVER HAD STI & & 73.8 \\
\hline Yes & 27 & \\
\hline No & & 137 \\
\hline HEARD OF HPV OR THE HPV VACCINE BEFORE & 16.5 \\
\hline Yes & & \\
\hline No & & \\
\hline HAVE RECEIVED THE HPV VACCINE & \\
\hline Yes & & \\
\hline No & & \\
\hline & & \\
\hline
\end{tabular}

\subsection{Awareness and knowledge of human papillomavirus (HPV)}

A comparison of respondents' correct responses regarding knowledge about HPV is given in Table 1. This was recorded when respondents were asked if they had ever heard about HPV and the HPV vaccine. From Table 2, it is seen that while $83.5 \%$ of respondents stated that they had previously heard about HPV and the HPV vaccine, only $61.6 \%$ of respondents were able to correctly answer that HPV is a sexually transmitted disease while $25 \%$ of respondents were undecided. Only 38.4\% knew that HPV could be transmitted by oral sex and 32.9\% knew that HPV infection can lead to cervical cancer in females and $55.5 \%$ felt that it only affects women. In a determination of significance between responses, it was determined that there was a significant difference between respondents' responses (The f-ratio value is 22.0163. The $\mathrm{p}$-value is $<.00001$. The result is significant at $\mathrm{p}<.05$ ). 
Table 2 Correct responses regarding knowledge about HPV and vaccine for HPV

\begin{tabular}{|l|l|l|l|}
\hline Question & \multicolumn{3}{|l|}{ Response Percentage (N = 164) } \\
\hline & Yes & No & Undecided \\
\hline HPV is a sexually transmitted disease & 61.6 & 13.4 & 25 \\
\hline HPV can be transmitted through oral sex & 38.4 & 26.8 & 34.8 \\
\hline There are different types of HPV & 48.8 & 7.9 & 43.3 \\
\hline HPV infection is linked to cervical cancer & 32.9 & 3.7 & 63.4 \\
\hline HPV only affects women & 55.5 & 9.8 & 34.8 \\
\hline HPV affects both genders equally & 32.3 & 21.3 & 46.3 \\
\hline HPV can cause genital warts & 40.9 & 18.9 & 40.2 \\
\hline Pap smears can help in the detection of HPV & 43.3 & 14.6 & 42.1 \\
\hline
\end{tabular}

The results regarding awareness of HPV appears to be high when compared to the study done by [16] who reported that $45 \%$ of participants knew about HPV and 55\% had no knowledge about the virus. Also, [17] reported that students they studied, exhibited low levels of knowledge about HPV and that the level of accuracy about HPV was higher in females than in males. In this current study, 32.9\% knew that HPV infection could possibly lead to cervical cancer and $55.5 \%$ felt that it only affects women. [18] reported that $7.5 \%$ of men and $19.0 \%$ of women knew that HPV infection was a risk factor for cervical cancer.

Based on the results of this study, it may be said that female student awareness of HPV was higher than that of male students and male students appeared to demonstrate less overall knowledge about HPV than female students. This is in agreement with the literature, which states that men and women exhibit different levels of knowledge and awareness about HPV.

Figure 1 shows the result of the mean knowledge of respondents about HPV. This was measured on a scale of 1 -3. On this scale, 1 meant that respondents had no knowledge, 2 meant that respondents had a fair knowledge and 3 meant that respondents had very good knowledge. From the results it is observed that the area that respondents had the highest mean knowledge level (2.29) was when asked "what does the acronym HPV mean". Low levels of knowledge were recorded for knowledge about whether cervical cancer is preventable (mean =1.87) and whether HPV can cause cervical cancer $($ mean $=1.79$ ).

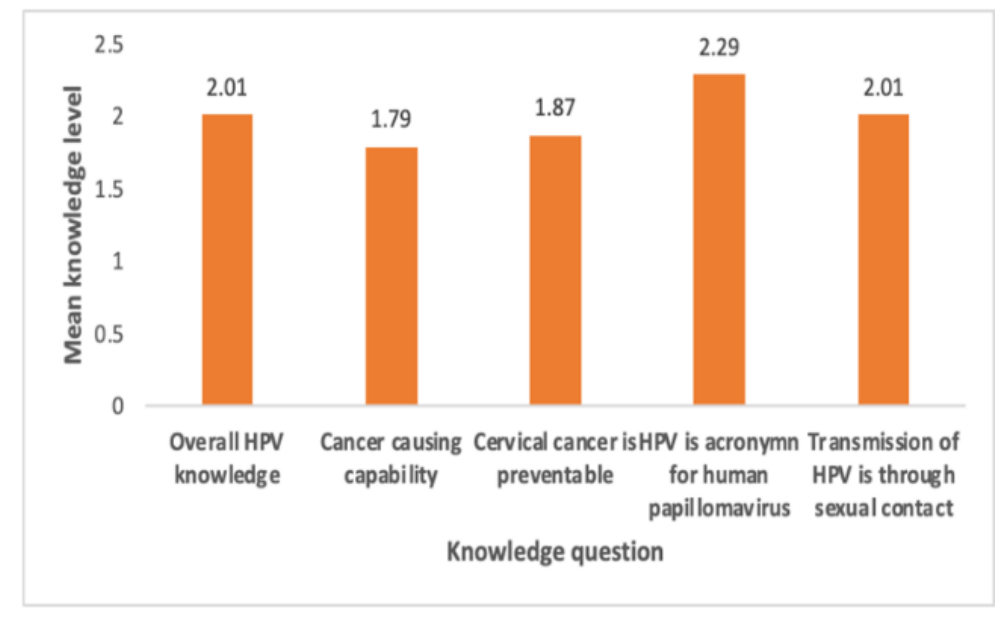

1 - No knowledge; 2 - Good knowledge; 3 - very good knowledge

Figure 1 Mean knowledge levels of respondents about HPV

To determine if a gender relationship existed, a comparison of the correctness of responses from male and female respondents' regarding knowledge of HPV was done and the results are shown in Table 3. 
Table 3 Gender difference in knowledge about HPV

\begin{tabular}{|c|c|c|c|c|}
\hline \multirow[b]{2}{*}{ Knowledge variable } & \multirow[b]{2}{*}{ Agreement } & \multicolumn{2}{|c|}{ Frequency (\%) } & \multirow{2}{*}{$\begin{array}{l}\text { p value for level of } \\
\text { significance }\end{array}$} \\
\hline & & Male & Female & \\
\hline \multirow{3}{*}{$\begin{array}{l}\text { HPV is a sexually transmitted } \\
\text { disease }\end{array}$} & Agree & $25(15.2)$ & $68(41.5)$ & \multirow{24}{*}{$\begin{array}{l}\mathrm{p} \text {-value is } .000188 \\
\text { The result is significant } \\
\text { at } \mathrm{p}<.05) \text {. }\end{array}$} \\
\hline & Disagree & $5(3)$ & $17(10.4)$ & \\
\hline & Undecided & $20(12.2)$ & 29 17.7) & \\
\hline \multirow{3}{*}{$\begin{array}{l}\text { HPV can be transmitted through } \\
\text { oral sex }\end{array}$} & Agree & $25(15.2)$ & $45(27.4)$ & \\
\hline & Disagree & $18(11)$ & $26(15.9)$ & \\
\hline & Undecided & $23(14)$ & $27(16.5)$ & \\
\hline \multirow[t]{3}{*}{ There are different types of HPV } & Agree & $24(14.6)$ & $56(34.1)$ & \\
\hline & Disagree & $2(1.2)$ & $11(6.7)$ & \\
\hline & Undecided & $31(18.9)$ & $40(24.4)$ & \\
\hline \multirow{3}{*}{$\begin{array}{l}\text { Some HPV types develop cancer in } \\
\text { females }\end{array}$} & Agree & $26(15.9)$ & $88(53.7)$ & \\
\hline & Disagree & $2(1.2)$ & $4(2.4)$ & \\
\hline & Undecided & $23(14)$ & $21(12.8)$ & \\
\hline \multirow[t]{3}{*}{ HPV affects only women } & Agree & $24(14.6)$ & $67(40.9)$ & \\
\hline & Disagree & $3(1.8)$ & $13(7.9)$ & \\
\hline & Undecided & $23(14)$ & $34(20.7)$ & \\
\hline \multirow[t]{3}{*}{ HPV affects both genders equally } & Agree & $22(13.4)$ & 31 (18.9) & \\
\hline & Disagree & $10(6.1)$ & $25(15.2)$ & \\
\hline & Undecided & $29(17.7)$ & $65(39.6)$ & \\
\hline \multirow[t]{3}{*}{ HPV can cause genital warts } & Agree & $16(9.8)$ & $55(33.5)$ & \\
\hline & Disagree & $10(6.1)$ & $21(12.8)$ & \\
\hline & Undecided & $22(13.4)$ & $40(24.4)$ & \\
\hline \multirow[t]{3}{*}{ Pap smears can help detect HPV } & Agree & $16(9.8)$ & $56(34.1)$ & \\
\hline & Disagree & $7(4.3)$ & $17(10.4)$ & \\
\hline & Undecided & $28(17.1)$ & $40(24.4)$ & \\
\hline
\end{tabular}

The results showed that the knowledge that female students had about HPV was more accurate than the knowledge displayed by male students. When an ANOVA test was done on the results about knowledge of HPV between males and females, the difference was significant at $\mathrm{p}<.05$ (f-ratio value $=30.31648$. The $p$-value is $<.00001$. This indicates that there was a significant difference in the knowledge of HPV when a gender comparison was done.

Based on the results (Table 3) it was observed that the knowledge level of female students about HPV was more accurate than that of male students. When an ANOVA test was done on the results about knowledge of HPV, the difference was significant (f-ratio value $=16.48914$. The $\mathrm{p}$-value is .000188 . The result is significant at $\mathrm{p}<.05$ ). This is similar to what was reported by [19] who stated that significant differences in HPV knowledge existed between genders and that female participants in their study displayed greater overall HPV knowledge than male participants. However, [20] in a study that examined knowledge and awareness of HPV and HPV vaccines among Caribbean youth with specific reference to the Bahamas, reported no statistically significant difference in mean HPV knowledge score between males and females, or HPV vaccine knowledge scores, between males and females. 


\subsection{Attitude towards the HPV vaccine}

Table 4 summarizes the responses to questions that sought to investigate respondents' attitude towards the HPV vaccine.

Table 4 Attitude towards the HPV vaccine

\begin{tabular}{|c|c|c|c|c|}
\hline \multirow[b]{2}{*}{ Attitude } & \multirow[b]{2}{*}{ Agreement } & \multicolumn{2}{|c|}{$\begin{array}{l}\text { Frequency } \\
\mathrm{N}(\%)\end{array}$} & \multirow{2}{*}{$\begin{array}{l}p \text { value for level of } \\
\text { significance } \\
p \text { value }\end{array}$} \\
\hline & & Male & Female & \\
\hline \multirow{3}{*}{$\begin{array}{l}\text { I doubt that the vaccine protects } \\
\text { against HPV }\end{array}$} & Agree & $10(6.1)$ & $15(9.1)$ & \multirow{24}{*}{$\begin{array}{l}\text { The result is significant } \\
\text { at } p<.05 \text { ). }\end{array}$} \\
\hline & Disagree & $22(13.4)$ & $45(27.4)$ & \\
\hline & Undecided & $36(22)$ & $36(22)$ & \\
\hline \multirow{3}{*}{$\begin{array}{l}\text { I believe that the HPV vaccine may } \\
\text { have too many side-effects }\end{array}$} & Agree & $13(7.93)$ & $26(15.9)$ & \\
\hline & Disagree & $15(9.1)$ & $31(18.9)$ & \\
\hline & Undecided & $25(15.2)$ & $54(32.9)$ & \\
\hline \multirow[t]{3}{*}{ I am generally against vaccination } & Agree & $8(4.9)$ & $22(13.4)$ & \\
\hline & Disagree & $30(18.3)$ & $60(36.6)$ & \\
\hline & Undecided & $16(9.8)$ & $28(17.1)$ & \\
\hline \multirow{3}{*}{$\begin{array}{l}\text { I don't have any particular reason } \\
\text { against the vaccine }\end{array}$} & Agree & $28(17.1)$ & $43(26.2)$ & \\
\hline & Disagree & $9(5.5)$ & $20(12.2)$ & \\
\hline & Undecided & $20(12.2)$ & 44 (26.8) & \\
\hline \multirow{3}{*}{$\begin{array}{l}\text { I believe HPV is costly and I can't } \\
\text { afford it }\end{array}$} & Agree & $12(7.3)$ & $16(9.8)$ & \\
\hline & Disagree & $11(6.7)$ & $43(26.2)$ & \\
\hline & Undecided & $30(18.3)$ & $52(31.7)$ & \\
\hline \multirow[t]{3}{*}{ I do not think that the vaccine is safe } & Agree & $14(8.5)$ & $25(15.2)$ & \\
\hline & Disagree & $17(10.4)$ & $29(17.7)$ & \\
\hline & Undecided & $27(16.5)$ & $52(31.7)$ & \\
\hline \multirow[t]{3}{*}{ I have doubts about its effectiveness } & Agree & $15(9.1)$ & $27(16.5)$ & \\
\hline & Disagree & $15(9.1)$ & $41(25)$ & \\
\hline & Undecided & $22(13.4)$ & $44(26.8)$ & \\
\hline \multirow{3}{*}{$\begin{array}{l}\text { I do not know where to get the HPV } \\
\text { vaccine }\end{array}$} & Agree & $17(10.4)$ & $24(14.6)$ & \\
\hline & Disagree & $17(10.4)$ & $61(37.2)$ & \\
\hline & Undecided & $19(11.6)$ & $26(15.9)$ & \\
\hline
\end{tabular}

The results show that there was a significant difference (p-value $=0.020989$ ) in attitudes between males and females towards the HPV vaccine. There appears to be a general concern about the safety and effectiveness of the vaccine among both male and female students. This is alluded to by the fact that among both male and female students the majority of students were undecided. In the case of safety males $(16.5 \%)$ and females $(31.7 \%)$ were undecided. In the case of attitude toward effectiveness, $13.4 \%$ ) of male students and $26.8 \%$ of female students were undecided. Also, when the question of cost of vaccine was addressed, the majority of respondents from among both males (18.3\%) and females $(31.7 \%)$ were undecided. When the responses to these three questions are examined one gets the impression that respondents had displayed such an attitude because they were not fully aware of the information that was disseminated about the HPV vaccine. In Guyana, the vaccine is free and because so many respondents were undecided and agreed with the statement that the vaccine was costly may be indicative of the fact that they were unaware of the fact that the 
vaccine was free. Therefore, one might infer that there is a need for greater information dissemination about the vaccine and where it can be accessed.

\subsection{Source of information about HPV and HPV vaccine}

Table 5 and Figure 2 show the responses regarding the various sources of information about HPV and the HPV vaccine as given by respondents. Most respondents cited components of mass media, internet (40.85\%) and television (25.61\%) as the main source of information about HPV and the HPV vaccine. In terms of the least indicated sources of information about HPV and HPV vaccine, medical personnel (6.1\%), public health seminars (2.44\%) and the University counsellor $(6.1 \%)$ were given.

Table 5 Source of information about HPV and the HPV vaccine

\begin{tabular}{|l|l|l|}
\hline Source of information & Frequency & Percentage \\
\hline Internet & 67 & 40.85 \\
\hline Newspaper & 12 & 7.32 \\
\hline Television & 42 & 25.61 \\
\hline Public health seminars & 4 & 2.44 \\
\hline Friends and relatives & 26 & 15.85 \\
\hline Medical personnel & 10 & 6.10 \\
\hline University counsellor & 3 & 1.83 \\
\hline
\end{tabular}

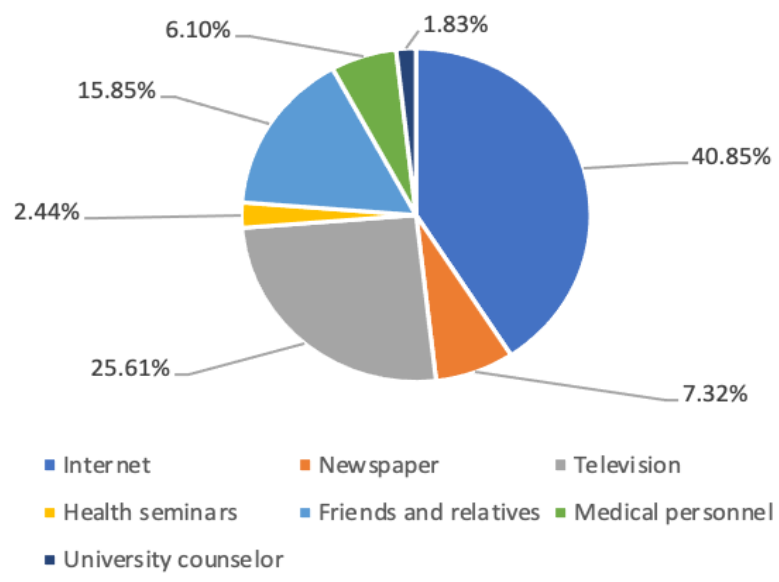

Figure 2 Source of information about HPV and the HPV vaccine

These results, in terms of the main source of information, tend to be similar to what was reported by [21] [4] and [22], where mass media was cited as the main source of information about HPV and HPV vaccines. However, [23] had reported that television and radio were not considered as the most appropriate or enough to improve knowledge about HPV. They argued that the level of schooling can influence how persons understand the information being provided.

In this current study, a small number of respondents indicated that their source of information about HPV and the vaccine were from medical personnel (6.1\%); public health seminars (2.44\%) and the university counsellor (1.83\%). This is not similar to results reported from another local study which indicated that that a major role in terms of information dissemination was played by medical and other health personnel [4]. Given the direct interaction that medical personnel and health professionals have with members of the public it is opportune for them to play a pivotal role in information dissemination in an effort to improve the level of knowledge, awareness of HPV and acceptability of the HPV vaccine [24] [25]. However, one might even argue that geographic differences, culture and accessibility to health care facilities may have impacted the results obtained in this current study. Also, the study reported by [8] used 
a different population and sample from a different Administrative region in Guyana and as such the sample would have had different demographic characteristics.

\subsection{Willingness to accept the HPV vaccine and factors that influence students' willingness}

Table 1 shows that while $83.5 \%$ of respondents heard about either HPV or the HPV vaccine, none of the respondents had ever received the HPV vaccine and $40.9 \%$ of respondents were willing to take the HPV vaccine (Table 6). Different reasons were offered for their unwillingness to take the HPV vaccine as shown in Table 6 and Figure 3.

Table 6 Willingness to accept the HPV vaccine and influencing factors

\begin{tabular}{|l|l|l|}
\hline Variable & \multicolumn{2}{|l|}{ (N = 164) } \\
\hline Willingness to get the vaccine $(\mathbf{N}=\mathbf{1 6 4})$ & Frequency & Percentage \\
\hline Willing & 67 & 40.9 \\
\hline Unwilling & 97 & 59.1 \\
\hline Reason for unwillingness to take the hpv vaccine $(\mathrm{n}=97)$ & $(\mathrm{N}=97)$ \\
\hline I don't think I am at risk of having HPV & 11 & 11.3 \\
\hline Need more information about the vaccine and side effects & 34 & 35.1 \\
\hline HPV is not a serious infection & 15 & 15.5 \\
\hline I do not think that the vaccine can prevent cervical cancer & 16 & 16.5 \\
\hline I do not think that the vaccine is safe & 21 & 21.6 \\
\hline
\end{tabular}

The main reason for the unwillingness to take the vaccine as indicated by $35.1 \%$ of respondents was that more information was needed. A similar result was reported by [26] that limited knowledge about the HPV vaccine was the main reason for respondents' unwillingness to take the vaccine and for not recommending it to others. Also, $21.6 \%$ of the respondents who were unwilling to take the vaccine thought that the vaccine was unsafe and $16.5 \%$ did not think that the vaccine could prevent cervical cancer.

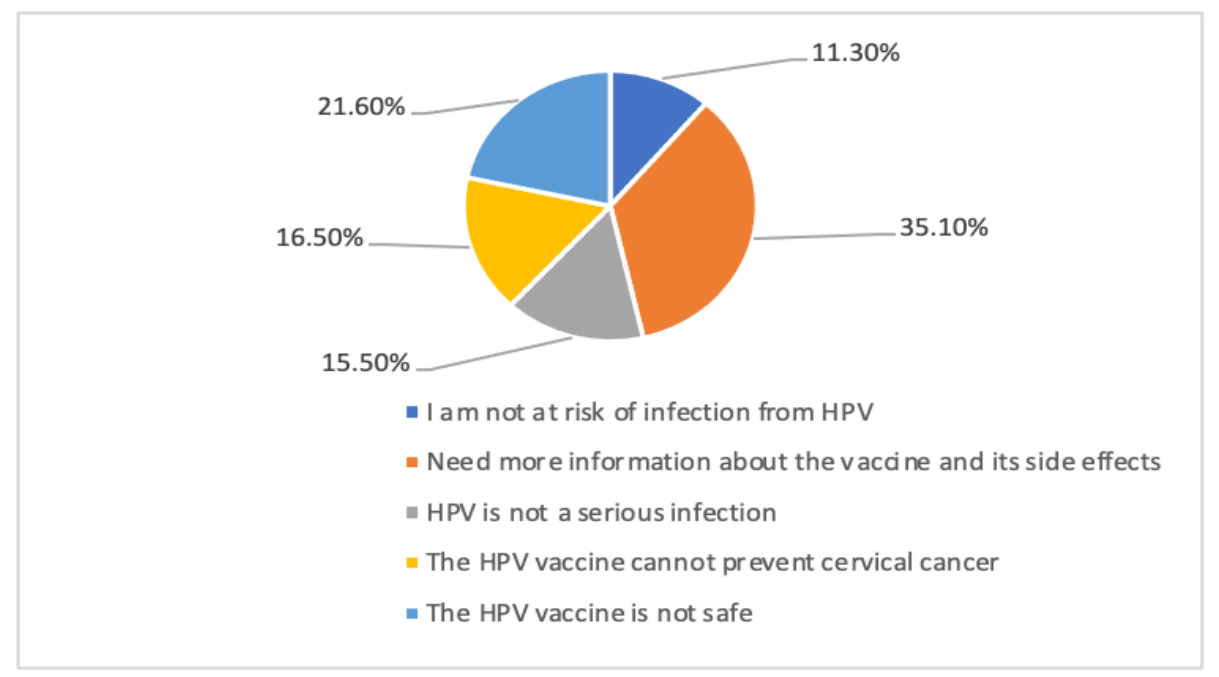

Figure 3 Reasons for respondents' unwillingness to take the HPV vaccine

\section{Conclusion}

Overall, the results from this study show that students at the UGBC had a somewhat low to fair level of knowledge about HPV and the HPV vaccine. This may have also impacted the level of willingness of respondents to accept the HPV vaccine. There was a significant difference in the HPV and HPV vaccine knowledge levels and attitudes to HPV and the HPV 
vaccine between male and female students. $83.5 \%$ of the respondents were aware of HPV and the availability of the HPV vaccine. However, $40.9 \%$ of the respondents were willing to get vaccinated for HPV.

There is an urgent need for the relevant authorities to undertake increased awareness and education programmes in the public health sector to inform the general populace about HPV, the HPV vaccine and cervical cancer. Such improved programmes should also target the most vulnerable key demographics while paying attention to the factors that seem to influence the decision to receive the HPV vaccine. Any awareness and education programme that is designed should also pay attention to the gender aspect and develop a targeted approach that pays attention to the gender differences that exist in knowledge about HPV and HPV vaccine.

Although targeting specific demographics in the initial vaccination roll out phase may have been a good idea, the time is probably right for the HPV vaccination programme to be made readily available at all hospitals and community health centers in each administrative region throughout Guyana. In this way, access to the vaccine may be improved and the opportunity to impact community education about HPV and HPV vaccines could be increased. In addition, information about the importance of pap smears, cervical cancer and HPV linkages could be strategically integrated.

Components of the mass media (internet and television) and family and friends were the three main sources of information about HPV and the HPV vaccine. The use of these popular sources of information will require a welldesigned education and awareness programme to be designed if it to be effective and reach vulnerable demographics in the Guyanese society. Such a programme should consider the other sources identified so as not to exclude any possible source of information since they are utilized by a sector of the populace.

Although there are factors that influence the level of knowledge, awareness and the attitudes of respondents to HPV and the HPV vaccine, these will need to be studied further to truly evaluate their relative impacts and influence on the development of strategic approaches to improve the effectiveness of local HPV education and awareness programmes.

\section{Compliance with ethical standards}

\section{Acknowledgments}

The willingness of respondents to participate in this study is acknowledged and the contributions of Mr. Phillip Da Silva, Mr. Dharamdeo Singh and Miss Donellie Ceasar are recognised. Gratitude is extended to the administrators of UGBC for granting permission to conduct the study on its campus.

\section{Disclosure of conflict of interest}

The authors hereby declare that this manuscript does not have any conflict of interest.

\section{Statement of informed consent}

Informed consent was obtained from all individual participants included in the study.

\section{References}

[1] Ault KA. Epidemiology and natural history of human papillomavirus infections in the female genital tract. Infect Dis Obstet Gynecol. 2006; Retrieved from: https://pubmed.ncbi.nlm.nih.gov/16967912/

[2] Mao C, Hughes JP, Kiviat N, Kuypers J, Lee SK, Adam DE et al. Clinical findings among young women with genital human papillomavirus infection. Am J Obstet Gynecol. 2003; 188: 677- 84.

[3] Arbyn M, Weiderpass E, Bruni L, de Sanjosé S, Saraiya M, Ferlay J, Bray F. Estimates of incidence and mortality of cervical cancer in 2018: a worldwide analysis. Lancet Glob Health. Feb 2020; 8(2): e191-e203.

[4] Oluwasola TA, Bello 00, Odukogbe AA. Awareness and attitude of female undergraduates toward human papillomavirus vaccine in Ibadan. Trop J Obstet Gynaecol. 2019; 36: 33-8.

[5] Burd EM. Human Papillomavirus and Cervical Cancer. 2003.

[6] Lkhagvasuren N. Human papillomavirus (HPV) and cervical cancer. 2008.

[7] World Health Organization. Human papillomavirus and related cancers: Guyana. Summary report update. WHO/ICO HPV Information Centre. 15 Sep 2010. 
[8] Tyrell E, Ramsammy-Boyce K. Knowledge and Perceptions of HPV and the HPV Vaccine among Pre-adolescent Girls and Their Guardians in Georgetown, Guyana. West Indian Med J. Jan 2015; 64(1): 43-8.

[9] Centre NC. Human Papillomavirus (HPV) Vaccines. 2015.

[10] Henderson L, Clements A, Damery S, Wilkinson C, Austoker J, Wilson S et al. 'A false sense of security'? Understanding the role of the HPV vaccine on future cervical screening behaviour: a qualitative study of UK parents and girls of vaccination age. J Med Screen. 2011; 18: 41-5.

[11] Yörük S, Açıkgöz A, Ergör G. Determination of knowledge levels, attitude and behaviors of female university students concerning cervical cancer, human papiloma virus and its vaccine. BMC Womens Health. 3 Aug 2016; 16: 51 .

[12] Dempsey AF, Zimet GD, Davis RL, Koutsky L. Factors that are associated with parental acceptance of human papillomavirus vaccines: a randomized intervention study of written information about HPV. Pediatrics. 2006; 117: 1486-93.

[13] Turiho AK, Okello ES, Muhwezi WW, Katahoire AR. Perceptions of human papillomavirus vaccination of adolescent schoolgirls in western Uganda and their implications for acceptability of HPV vaccination: a qualitative study. 2017.

[14] Khan TM, Buksh MA, Rehman IU, Saleem A. Knowledge, attitudes, and perception towards human papillomavirus among university students in Pakistan. Papillomavirus Res. 2016; 2: 122-7.

[15] Bruni L, Albero G, Serrano B, Mena M, Gómez D, Muñoz J, Bosch FX, de Sanjosé S. ICO/IARC Information Centre on HPV and Cancer (HPV Information Centre). Human Papillomavirus and Related Diseases in Guyana. Summary Report. 17 June 2019.

[16] Dursun P, Senger SS, Arslan H. et al. Human papillomavirus (HPV) prevalence and types among Turkish women at a gynecology outpatient unit. BMC Infect Dis. 2009; 9: 191.

[17] Medeiros R, Ramada D. Knowledge differences between male and female university students about human papillomavirus (HPV) and cervical cancer: Implications for health strategies and vaccination. Vaccine. 16 Dec 2010; 29(2): 153-60.

[18] Oh JK, Lim MK, Yun EH, Lee EH, Shin HR. Awareness of and attitude towards human papillomavirus infection and vaccination for cervical cancer prevention among adult males and females in Korea: a nationwide interview survey. Vaccine. 17 Feb 2010; 28(7): 1854-60.

[19] Kasymova, S., Harrison, S. E., \& Pascal, C. (2019). Knowledge and Awareness of Human Papillomavirus Among College Students in South Carolina. Infectious diseases, 12.2019. Retrieved from: https://journals.sagepub.com/doi/full/10.1177/1178633718825077

[20] Clemon George, Robin Roberts, Delon Brennen, Lynette Deveaux, Stanley E Read. Knowledge and awareness of Human Papillomavirus (HPV) and HPV vaccines among Caribbean youth: the case of the Bahamas, Human Vaccines \& Immunotherapeutics. 2020; 16(3): 573-580,

[21] Ojiyi E, Dike Ie, Okeudo C, Ejikem C, Nzewuihe A, Agbata A. Local risk factors in genital human papilloma virus infection in cervical smears. Ann Med Health Sci Res. Oct 2013; 3(4): 529-35.

[22] Rosen, B. L., Shew, M. L., Zimet, G. D., Ding, L., Mullins, T., \& Kahn, J. A. Human Papillomavirus Vaccine Sources of Information and Adolescents' Knowledge and Perceptions. Global pediatric health, 4. 2017. Retrieved from: https://www.ncbi.nlm.nih.gov/pmc/articles/PMC5703096/

[23] Almeida CM, Tiro JÁ, Rodriguez MA, Diamant AL. Evaluating associations between sources of information, knowledge of the human papillomavirus, and human papillomavirus vaccine uptake for adult women in California. Vaccine. 2012; 30(19): 3003-8.

[24] Lee Mortensen G, Adam M, Idtaleb L. Parental attitudes towards male human papillomavirus vaccination: a panEuropean cross-sectional survey. BMC Public Health. 2015; 15: 624.

[25] Santos ACd, Silva NNT, Carneiro CM et al. Knowledge about cervical cancer and HPV immunization dropout rate among Brazilian adolescent girls and their guardians. BMC Public Health. 2020; 20: 301.

[26] Liu Y, Di N, Tao X. Knowledge, practice and attitude towards HPV vaccination among college students in Beijing, China. Hum Vaccin Immunother. 2020; 16(1): 116-123. 